\title{
Süt dişlerinde restoratif materyal seçimi ve etkileyen faktörler
}

\author{
Merve Safa Mutluay ${ }^{1}$, Abidin Talha Mutluay ${ }^{2}$
}

Selcuk Dent J, 2016; 3: 151-158

Basvuru Tarihi: 03 Mayıs 2016 Yayına Kabul Tarihi: 30 Kasım 2016

\section{Öz \\ Süt dişlerinde restoratif materyal seçimi ve etkileyen faktörler}

Son yıllarda, çürüklü süt dişlerinin restorasyonunda kullanılan materyallerde yeni gelişmeler elde edilmiştir. Süt ve karışık dişlenme döneminde estetik özellikleri nedeniyle sıklıkla tercih edilen cam iyonomer siman, rezin modifiye cam iyonomer, poliasit modifiye kompozit rezin (kompomer) ve kompozit rezin gibi materyaller günden güne geliştirilmektedir. Süt dişlenmede diş renginde restoratif materyallerin kullanımı, düşük başarısızlık oranlarıyla birlikte konservatif kavite preperasyonlar için oldukça avantajıdır. Ancak, yüksek çürük riskli hastaların ve pulpa tedavili dişlerin restorasyonunda estetik olmayan preforme metal kronlar tercih edilmelidir. $\mathrm{Bu}$ derlemede amacımız; süt dişi restorasyonlarında kullanılan restoratif materyaller hakkında bilgilerimizin güncellenmesi ve bu materyallerin avantaj ve dezavantajlarının tartışımasıdır.

\section{ANAHTAR KELIMELER}

Çocuk diş hekimliği; dental materyaller; dental rezinler

Süt dişlerinin morfolojik ve histolojik özelliklerinin daimi dişlerden farklı olması, restoratif materyal gereksinimlerinin de farklı olmasını gerektirir (American Academy on Pediatric Dentistry Council on Clinical Affairs 2008). Süt dişlerinin mine ve dentin kalınlığının ince, tüberküller arası ve oklüzal mesafenin küçük, proksimal kontakların düz olması, servikal mine rodlarının oklüzale doğru yönlenmesi, kronun servikal bölgede aniden daralma göstermesi süt dişlerine uygulanan restorasyonların başarısını önemli ölçüde etkilemektedir (Gross ve ark. 2001, American Academy on Pediatric Dentistry Council on Clinical Affairs 2008, American Academy on Pediatric Dentistry Council on Clinical Affairs 2014). Bunun yanında süt dişlerinin ağızda kaldıkları sürenin kısa ve

\section{ABSTRACT \\ The choices of restorative materials in primary teeth and influencing factors}

New developments in the materials used for restorations of carious primary molars have obtained in recent years. The materials which are preferred due to esthetic features frequently such as conventional glass ionomer cements, resin-modified glass ionomer cements, polyacid modified composites (compomers) and composite resins are being developed day to day. Tooth coloured restorative materials allow conservative cavity preparation and have low failure rate which are advantageous when used restorations in primary teeth However, preformed metal crowns should be preferred for restoration of high caries risk patient' and pulp therapied teeth. The purpose of this review is to update our informations about dental restorative materials used in primary tooth restorations and to discuss advantages and disadvantages of these materials.

\section{KEYWORDS}

Pediatric dentistry; dental materials; dental resins

çocuk hastada çalışma süresinin kısıtlı olması da restoratif materyal seçimini etkilemektedir (Hickel ve ark. 2005).

Modern diş hekimliğinde diş dokularının minimal oranda kaldırıması ve diş dokularına bağlanabilen restoratif materyallerin uygulanması önem taşımaktadır (Fuks 2015). Süt ve karışık dişlenme döneminde, amalgam ve paslanmaz çelik kronların (PÇK) yanı sıra cam iyonomer ve kompomer gibi flor salan restoratif materyaller yaygın olarak kullanılmaktadır (Fleming ve ark. 2001, Somani ve ark. 2016). Öte yandan, teknolojinin ilerlemesine paralel olarak özellikleri günden güne geliştirilen cam iyonomer siman, rezin modifiye cam iyonomer siman

\footnotetext{
${ }^{1}$ Kırıkkale Üniversitesi Diş Hekimliği Fakültesi Pedodonti Anabilim Dalı, Kırıkkale

${ }^{2}$ Kırıkkale Üniversitesi Diş Hekimliği Fakültesi Restoratif Diş Tedavisi Anabilim Dalı, Kırıkkale
} 
(RMCi), poliasit modifiye kompozit rezin (kompomer) ve kompozit rezin gibi materyaller de diş çürüğünün tedavisinde sıklıkla tercih edilen restoratif materyallerdir (Fleming ve ark. 2001, Tran ve Messer 2003). Bu derlemede; süt dişlerinin restorasyonunda kullanılan restoratif materyaller hakkında bilgilerimizin güncellenmesi ve restoratif materyal seçiminde yol gösterici olunması amaçlanmaktadır.

\section{Amalgam}

Dental amalgam; gümüş, bakır, kalay ve civa gibi metallerin karışımdan oluşan restoratif bir materyaldir (Beazoglou ve ark. 2007). Süt ve daimi dişlerin Sınıf I ve II kavitelerinde, dayanıklılık ve kuvvet gerektiren, estetik kaygı olmayan durumlarda kullanılabilir. Süt dişlerinin küçük oklüzal lezyonlarını içeren sınıf I kavitelerde ise, amalgam restorasyonlardan ziyade, konservatif koruyucu restorasyonlar tercih edilmelidir (American Academy on Pediatric Dentistry Council on Clinical Affairs 2014). Dental amalgamın diş dokularına kimyasal olarak tutunmaması, minimal invaziv kavite preperasyonuna izin vermemesi, düşük fraktür dayanımı ve termal iletkenliklerinin yüksek olması dezavantajlarıdır. Bunun yanında dental amalgam, rezin esaslı materyallere göre daha az teknik hassasiyet ve nem kontrolü gerektimesi nedeniyle süt dişi restorasyonlarında tercih edilebilir (Figueiredo de Magalhaes ve ark. 2008, Dhar ve ark. 2015).

Sekonder çürük gelişimi çoğu zaman kavitede rezidiüel çürük bırakılması ya da hastanın çürük riskiyle ilişkilendirilmesine rağmen, uygulanan restoratif materyalin sekonder çürük gelişimine yatkın ya da önleyici etkisi olabileceğinden de bahsedilmektedir (Metz ve ark. 2015). Dental amalgamın sekonder çürük gelişimine rezin esaslı materyallere göre daha az yatkın olması amalgam restorasyonların başarı oranını artırmaktadır (Bernardo ve ark. 2007) Süt dişi Sınıf I kavitelerde amalgam restorasyonların 7 yıllık başarı oranı \%85-96 arasında bildirilirken, yıllık başarısızılık oranı \%3,2 olarak belirtilmiştir (Qvist ve ark. 2004, Hickel ve ark. 2005). Kompomer ve kompozit restorasyonların 5 yıllık takip süresince, amalgam restorasyonlara göre daha fazla yenilenmeye ihtiyaç duyduğu bildirilmiştir (Soncini ve ark. 2007).

Amalgamın son yıllarda daha az tercih edilmesinde, içeriğindeki civanın genel sağlık üzerine olumsuz etkileri olduğuna dair tartışmalar, çevresel kaygılar ve estetik materyal alternatiflerinin artması etkili olmuştur (American Academy on Pediatric Dentistry Council on Clinical Affairs 2014). Amalgamın güvenilirliğine dair 2004 ve 2008 yılındaki çalışmalar incelenerek hazırlanan kapsamlı bir literatür derlemesine göre, civa salınımı ile çeşitli medikal yakınmalar hakkında yeterli düzeyde kanıt bulunmadığı görülmektedir (Luglie ve ark. 2009). Bunun yanında Gıda ve İlaç Kurumu (FDA), dental amalgamı, civa buharının olası zararları olan ve civa hassasiyeti olan kişilerde kullanımı kontrendike Sınıf II (bir miktar risk taşıyan) bir materyal olarak tanımlamıştır. Amalgamın hamile bayanlarda, gelişen fetüste ve 6 yaş altındaki çocuklarda genel sağlık üzerine etkilerine dair uzun dönem kanıtların yetersiz olduğu bildirilmiştir (Food ve Drug Administration 2010).

\section{Konvansiyonel cam iyonomer siman}

Konvansiyonel cam iyonomer simanlar (KCis), mine ve dentine kimyasal olarak bağlanan biouyumlu materyallerdir. Materyalin sertleşmesi floroalüminasilikat cam tozu ile sulandırılmış poliakrilik asit arasındaki asit-baz reaksiyonu ile gerçekleşir (Santos ve ark. 2014). KCiS'ın kırılgan yapıları ve kuvvet altında uzun dönem performanslarının iyi olmaması en önemli dezavantajıdır (Somani ve ark. 2016).

Flor içeren dental materyaller (cam iyonomer siman, rezin modifiye cam iyonomer, poliasit modifiye kompozit rezin, giomer) tükürük, plak ve sert diş dokularındaki flor seviyesini artırmak için flor rezervuarı olarak görev yapabilir. Ayrıca, sekonder çürükleri önlemeye veya azaltmaya yardımcı olabilir (Exterkate ve ark. 2005). Restoratif materyallerden kısa ve uzun süreli flor salınımı; materyalin matriksine, sertleşme mekanizmasına ve flor içeriğine, içeriğindeki florun özelliğine ve çeşitli çevresel koşullara bağlıdır (Itota ve ark. 2005). Cis'ın sertleşmesi esnasında asit-baz reaksiyonu ile hızlı bir flor salınımı gerçekleşir, ardından flor salınım hızında önemli bir azalma gözlenir. Flor salınımının hızlı bir şekilde düşmesi, sertleşme reaksiyonunun ardından yüksek oranda flor salınımı yapan cam partiküllerinin, ilerleyen zamanlarda polialkenoat asit içinde çözünmesinden kaynaklanmaktadır (Forsten 1998). CiS'ın laboratuar şartlarında aproksimal çürük lezyonlarını önleme ve durdurma etkisinin olduğu, ancak bu etkinin uzun dönem klinik çalışmalarla doğrulanmadığı belirtilmektedir (Tedesco ve ark. 2016). Buna rağmen; KCis özellikle tedavi olanaklarına erişimin sınırlı olduğu sahalarda atravmatik restoratif tedavilerle (ART) uygulandığında, tatmin edici klinik performans ve sağ kalım oranları göstermektedir (Hesse ve ark. 2015). Süt azı dişlerinde yürütülen bir çalışmaya göre; KCiS'ın bağlanma dayanımları, sertleşme esnasında neme karşı hassasiyetlerinin yüksek olması nedeniyle rezin modifiye cam iyonomer simanlardan daha düşüktür. $\mathrm{Bu}$ durum özellikle çiğneme kuvvetinin yüksek olduğu alanlarda fraktür dayanımı ve basma-çekme dayanımının düşük olmasına neden olmaktadır (Somani ve ark. 2016).

90'lı yılların başında KCiS'ın mevcut dezavantajlarının giderilmesi amacıyla, yüksek viskositeli toza poliakrilik asit eklenerek yüksek viskositeli cam iyonomer simanlar (YVCiS) üretilmiştir. Bu sayede materyalin aşınma ve abrazyon direnci gibi fiziksel özellikleri geliştirilmiştir (Guggenberger ve ark. 1998). 
YVCis; biyouyumluluk, diş dokularına kimyasal adezyon, flor salınımı ve tekrar flor depolama gibi özellikleri nedeniyle özellikle Sınıf I ve II kaviteye sahip süt dişlerinin restorasyonunda tercih edilebilir (Frencken ve ark. 1996). Ancak materyalin klinik davranışlarının daha iyi anlaşılması için uzun dönem takipli klinik çalışmalara intiyaç duyulmaktadır (Bonifacio ve ark. 2009).

\section{Rezin modifiye cam iyonomer siman}

KCiS'a rezin monomerlerin katılmasıyla rezin modifiye cam iyonomer simanlar (RMCis) geliştirilmiş, bu sayede materyalin aşınma ve fraktür direnci, neme karşı hassasiyet gibi mekanik özelliklerinde iyileşme elde edilmiştir (Mickenautsch ve ark. 2010). RMCis, süt dişlerinde amalgam ve rezin bazlı kompozitlere alternatif olarak kullanılabilir (Croll ve ark. 2001). RMCis, KCis gibi diş dokularına kimyasal olarak bağlanabilme ve flor salabilme özelliklerine sahiptir. Ayrıca, rezin içeriği nedeniyle kolay hazırlanma ve uygulama, uzun ve kontrollü çalışma süresi gibi özellikleriyle de süt dişlerinde kullanım kolaylığı sağlamaktadır (Kotsanos ve Arizos 2011). Materyale rezin matriksin eklenmesi, bu rezin bazlı simanların kompozit restorasyonlara adezyonuna ve süt ve daimi diş kavitelerinde liner yada baz materyal olarak kullanılmasına izin vermektedir. (Kramer ve Frankenberger 2007). Süt dişi sınıf II kavitelerinde KCiS yerine RMCiS'ın uygulanması avantaj sağlayabilir (Chadwick ve Evans 2007). Süt dişlerinin sınıf II restorasyonlarında, RMCiS'ın klinik olarak amalgam kadar başarılı olduğu ve RMCis ile restore edilen dişlerde restorasyon kenarlarında daha az rekürrent çürük görüldüğü belirtilmiştir (Donly ve Garcia-Godoy 2002).

RMCiS'ın sertleşmesi hem asit-baz reaksiyonunu hem de hidroksietil metakrilat (HEMA) monomerlerinin polimerleşmesini içerir. Hidrofilik bir rezin olan HEMA materyalin su emilimini artırarak fiziksel ve mekanik özelliklerini etkileyebilir (Roberts ve ark. 2009). Materyalin biyouyumluluğu ile yakından ilişkili olan HEMA salınımı, dentin tübüllerinden difüze olarak pulpa hücrelerine sitotoksik etki gösterebilir. Bu sebeple uygulama esnasında üretici firmanın talimatlarına ve önerilen polimerizasyon süresine dikkat edilmesi gerekir (Kan ve ark. 1997).

\section{Kompozit rezin}

Ebeveynlerde amalgam restorasyonların kullanımıyla ilgili genel bir kaygı oluşması üzerine, kompozit rezinlerin ve diş rengindeki diğer estetik materyallerin süt dişlerinde kullanımı yaygınlaşmıştır (Burgess ve ark. 2002, Yeolekar ve ark. 2015). Kompozit rezinler; kontrollü sertleşme özellikleri olan ve diş yapılarına adeziv olarak tutunan (Bağlar ve ark. 2015), pediatrik diş hekimliğinde koruyucu rezin restorasyonlar, ön diş restorasyonlar, Sınıf I ve II restorasyonlarda tercih edilen estetik materyallerdir (Burgess ve ark. 2002, Donly ve Garcia-Godoy 2002).

Kompozit restorasyonların hassas bir teknik gerektirmesi, kaviteye uygulanmasının amalgam ve diğer restoratif materyallerden daha uzun sürmesi, Bisfenol A içeriği nedeniyle ile biyouyumluluğun azalması materyalin olumsuz özellikleridir. Bir diğer sorun; kompozit rezinin kavite duvarlarından uzaklaşmasına bağlı olarak adezyonunun bozulmasına ve marjinal boşlukların oluşmasına yol açan polimerizasyon büzülmesidir (Yeolekar ve ark. 2015). Marjinal boşluklar ise, postoperatif hassasiyet, renklenme, sekonder çürük ve başarısızlık olarak tanımlanabilecek pulpal patolojilere yol açabilmektedir (Al-Harbi ve Farsi 2007). Bu olumsuz etkileri en aza indirerek başarılı bir restorasyonun yapılmasında teknik hassasiyetle çalışılması ve dikkatli vaka seçimi önem taşımaktadır (Yeolekar ve ark. 2015, Loomans ve Hilton 2016).

Kompozit rezinler sınıf I kaviteye sahip süt dişlerinde \%85-100 oranında başarıya sahiptir (Hickel ve ark. 2005, Bernardo ve ark. 2007, Soncini ve ark. 2007). Gladys ve ark. (1997) materyallerin mekanik ve fiziksel özelliklerini test ettiği çalışmalarında, kompozit rezinlerin en yüksek, KCiS'ın en düşük, RMCiS'ın orta derecede çekmebasma dayanımına sahip olduğunu bildirmiştir. Bunun yanında, sekonder çürük gelişiminin kompozit restorasyonlarda amalgama göre 3,5 kat fazla olduğu rapor edilmiştir (Bernardo ve ark. 2007). Kompozit rezin ve RMCiS'ın kıyaslandığı başka bir çalışmada, süt dişlerindeki restorasyonların 18 aylık klinik performansı değerlendirilmiş; materyallerin sağ kalım oranları, restore edilen yüzey sayısı ve çürük kaldırma tekniğine bakılmaksızın her iki materyal istatistiksel olarak benzer bulunmuştur. Araştırıcılar, süt dişlerinde kullanılan rezin içerikli restoratif materyal tipinin restorasyonun ömrünü etkilemediğini öne sürmüştür (Casagrande ve ark. 2013).

\section{Kompomer}

Kompomerler, CiS'ın fiziksel ve mekanik özelliklerinin geliştirilmesiyle üretilen, kompozit rezinlere benzer özelliklere sahip flor salınımı yapan hibrit materyallerdir (Tran ve Messer 2003, Kramer ve Frankenberger 2007). Sınıf II ve V kavitelerin restorasyonunda, fissür sealant olarak ya da ortodontik bandların yapıştırılmasında kullanılabilir. Kompomerler flor salabilme yeteneği sayesinde çürük karşıtı materyaller olarak tanımlansa da, salınan flor oranı KCis ve RMCis ile kıyaslandığında daha düşüktür (Eberhard ve ark. 
1997). Bu nedenle, kompomerlerin kullanımı sadece düşük ve orta çürük riskli hastalarda tavsiye edilmekte, kompomer restorasyonların uzun dönemde rekürrent çürük ve aşınma açısından takip edilmesi önerilmektedir (Garcia-Godoy 2000, Kramer ve Frankenberger 2007).

Dental restoratif materyallerin manüplasyonü materyalin nihai karakterini belirlediği için oldukça önemlidir. Toz/likit formda bulunan materyallerin önerilen oranda ve ideal ısıda hazırlanmaması ve karıştırma hızı reaksiyonun daha hızlı ya da yavaş olarak gerçekleşmesine neden olabilir. Bu faktörler; materyalin mekanik ve kimyasal yapısını direkt olarak etkilemektedir. Bu sebeple hazır karışım ya da kapsül formda bulunan rezin esaslı materyallerin kullanımı toz/likit formda bulunan ve elle karıştırılan materyallere göre kişisel uygulama hatalarını en aza indirmektedir (Hatrick ve Eakle 2016).

Kompomer restorasyonlar, diş dokularına rezin tag'ların oluşumu ile mikromekanik olarak tutunurken, KCis mine ve dentindeki apatitlerin kalsiyumları ile poliasitlerinin karboksil gruplarının şelasyonu ile kimyasal olarak tutunur. Bu açıdan kompomerler kimyasal yapı olarak KCiS'dan çok kompozitlere benzemektedirler (Hickel ve ark. 2005). Kompomerler çekme-basma dayanımı ve aşınmaya direnci KCiS'dan daha üstün materyallerdir. Süt dişi sınıf II kavitelerde kompozit, kompomer, KCis ve RMCis'ın fraktür dayanımının karşılaştırıldığı çalışmada; kompomer ve kompozitin KCis ve RMCiS'a göre daha yüksek fraktür dayanımına sahip olduğu bildirilmiştir (Yildiz ve ark. 2015).

Kompozit rezinlerin çocuk hastada kullanımı daha zaman alıcı olsa da, doğru bir protokolle uygulandığında kompozit ve kompomer restorasyonların benzer klinik performansa sahip olduğu bildirilmiştir (Kramer ve Frankenberger 2007). Bazı Avrupa ülkelerinde süt dişlerinin restorasyonunda bu materyaller amalgam ile ilgili olarak sağlık otoritelerinin kısıtlamaları ve civa salınımından kaynaklanan yan etkiler nedeniyle tercih edilmektedir (Hickel ve ark. 2005). Aynı zamanda süt dişlerinde diş renginde materyallerin kullanımı ebeveynleri estetik açıdan tatmin etmektedir (Kopperud ve ark. 2012).

\section{Paslanmaz çelik kron}

Kronlar, uzun dönemde diğer restoratif materyallerde yaygın olarak görülen başarısızlık sebeplerini azaltmaktadır. Süt dişleri için kronlar birçok farklı boyutta üretilmekte ve yaygın çürüklü, pulpa tedavili ya da gelişimsel olarak defektli dişlerin restorasyonunda kullanılmaktadır (Innes ve ark. 2015). Kronlar tamamen "paslanmaz çelik" ten üretilebileceği gibi, daha iyi estetik sonuçlar için veneer ya da tümüyle seramik materyal ile kaplanabilmektedir. Çok yüzlü amalgam restorasyonlar ile kıyaslandığında PÇK'ların daha dayanıklı, yeniden tedavi ihtiyacını azaltan, uygulanması kolay ve hesaplı restoratif materyaller olduğu belirtilmektedir (Mata ve Bebermeyer 2006).

Literatüre bakıldığında; oklüzal strese maruz kalan süt azı dişi restorasyonlarında yıllık başarısızlık oranı; PÇK'lar için \%0-14, amalgam restorasyonlar için \%0-35,3, cam iyonomer restorasyonlar için \%025,8, kompomer restorasyonlar için \%0-15, kompozit restorasyonlar için \% 0-11 olarak tespit edilmiştir. Başlıca başarısızlık nedenleri olarak, sekonder çürük, marjinal eksiklikler, kırık ve aşınma gösterilmiştir (Hickel ve ark. 2005). Guelman ve Mjör (2002) tarafından yürütülen bir anket çalışması sonucunda, rezin bazlı materyallerin Sınıf I ve II restorasyonlarda, PÇK'nın ise 3 ya da daha çok yüzlü kavitelerde en çok tercih edilen materyaller olduğu bildirilmiştir. İki yıllık randomize kontrollü klinik bir çalışmada, pulpotomi uygulanan süt dişlerinde PÇK (\%95) ile RMCi/kompozit restorasyonların $(\% 92,5)$ başarı oranı benzer bulunmuştur (Atieh 2008).

\section{Giomer}

Cam iyonomer simanların geliştirilmesiyle üretilen yeni bir materyal olan giomerler, önceden reaksiyona girmiş cam partikülleri içeren rezin matriksten oluşan restoratif materyaldir. Flor salınım ve depolama özellikleri ile CiS'a estetik, cilalanabilirlik ve biyouyumluluk açısından ise rezin kompozitlere benzer özellik taşıdığı öne sürülmektedir (Yadav ve ark. 2012).

Süt dişlerinde yürütülen in-vitro bir çalışmada; kompomer, ormoser, giomer ve RMCiS'ın marjinal sızıntısı istatistiksel olarak benzer bulunmuştur (Yadav ve ark. 2012). Sınıf II kaviteye sahip 41 çocuk hastanın 146 süt dişinin farklı materyallerle (hibrit kompozit rezin, RMCis, kompomer, giomer kompozit rezin) restore edildiği klinik bir çalışmanın 24 aylık takip raporunda ise; biyolojik değerlendirme kriterleri açısından RMCis en başarılı, giomer rezin ise en uzun sağ kalım oranına sahip materyal olarak belirlenmiştir (Sengul ve Gurbuz 2015).

\section{8. Ön dişlerde kullanılan restoratif materyaller}

Kesici dişlerde üstünlüğü klinik çalışmalarla kanıtlanmış bir materyal bulunmamakta ve süt kesicilerin restorasyonunda rezin kompozitler, cam iyonomer siman, RMCi ve kompomer gibi birçok farklı materyal kullanılmaktadır. Diş rengindeki kompozit, kompomer, Cis, RMCis gibi materyallerin kullanımının yanında, bazı durumlarda rezin materyaller ile prefabrike kronların ya da paslanmaz çelik kron ile zirkonya kronlar birlikte kullanımıyla full kron uygulamaları gerekebilir. 
Klinisyenin, ebeveynin ve hastanın estetik beklentisi, hasta uyumu, sağlam diş dokusu, nem ve kanama kontrolü değişkenlerinin tümünü değerlendirerek uygulayacağı restoratif materyali seçmesi gerekir (Waggoner 2015).

\section{Biyolojik restorasyonlar}

Farklı bir yaklaşım olarak; kaybedilen ön ve arka bölge dişlerine ait lezyonlar, biyolojik restorasyonlarla tedavi edilebilir. Inn-vivo ve in-vitro çalışmalarda farklı hastalardan elde edilmiş kron ve köklerin, yer tutucu, kanal-içi post ya da ön-arka bölge dişlerinin biyolojik olarak restorasyonunda yardımcı bir materyal olarak kullanıldığı görülmektedir (Yang ve Chang 1990, Cardoso ve ark. 1994, White ve ark. 1994, RamiresRomito ve ark. 2000). Sterilizasyon ve saklama problemlerinin üstesinden gelindiğinde (White ve ark. 1994); biyolojik restorasyonlar servikal adaptasyon, fizyolojik aşınma, plak birikimi, fonksiyon ve estetik açıdan hastanın doğal dentisyonuna yakın sonuçlar elde edilmesini sağlayabilir (Ramires-Romito ve ark. 2000).

\section{SONUÇ}

Literatür incelendiğinde pediatrik diş hekimliğinde kullanılan restoratif materyallerle ilgili önemli miktarda bilgi olduğu görülmektedir. Bununla birlikte kavite dizaynı ve materyal seçiminde kesin bir kanı bulunmadığı ve materyal seçiminin klinisyenin tercihine bağlı olduğu gözükmektedir (Tran ve Messer 2003). Süt dişlerinin restorasyonunda; adeziv sistemlerle birlikte diş renginde restoratif materyallerin kullanımı minimal dizaynla konservatif kavite preperasyonlarına izin vermekte (Tran ve Messer 2003) ve sıklıkla tercih edilmektedir (Guelmann ve Mjor 2002). Yaygın çürüklü ve pulpa tedavili dişlerde ise preforme metal kronlar direkt restorasyonlara oranla tercih edilmesi gereken materyalledir (Kramer ve Frankenberger 2007). Kullanılacak restoratif materyale karar verme sürecinde, klinisyenlerin mevcut literatürler arasından kanıta dayalı sistematik değerlendirme ve randomize klinik çalışmalara önem vermesi önerilmektedir (Dhar ve ark. 2015). 


\section{KAYNAKLAR}

Al-Harbi SD, Farsi N, 2007. Microleakage of Ormocerbased restorative material in primary teeth: an in vivo study. J Clin Pediatr Dent, 32,13-17.

American Academy on Pediatric Dentistry Council on Clinical Affairs, 2008. Guideline on pediatric restorative dentistry. Pediatr Dent, 30,163-169.

American Academy on Pediatric Dentistry Council on Clinical Affairs, 2014. Clinical guideline on pediatric restorative dentistry. Pediatric dentistry,37, 232-243.

Atieh M, 2008. Stainless steel crown versus modified open-sandwich restorations for primary molars: a 2year randomized clinical trial. Int $\mathrm{J}$ Paediatr Dent, 18,325-332.

Bağlar S, Bayraktar Y, Ercan E, Mutluay AT, Şengün A, 2015. The challenge of MDP monomer containing adhesive systems: Comparison of shear bond strengths. Atatürk Üniv. Diş Hek Fak Derg, 25,258-265.

Beazoglou T, Eklund S, Heffley D, et al, 2007. Economic impact of regulating the use of amalgam restorations. Public Health Rep, 122,657-663.

Bernardo M, Luis $\mathrm{H}$, Martin MD, et al, 2007. Survival and reasons for failure of amalgam versus composite posterior restorations placed in a randomized clinical trial. J Am Dent Assoc, 138,775-783.

Bonifacio CC, Kleverlaan CJ, Raggio DP, et al, 2009. Physical-mechanical properties of glass ionomer cements indicated for atraumatic restorative treatment. Aust Dent J, 54,233-237.

Burgess JO, Walker R, Davidson JM, 2002. Posterior resin-based composite: review of the literature. Pediatr Dent, 24,465-479.

Cardoso AC, Arcari GM, Zendron MV, Magini Rde S, 1994. The use of natural teeth to make removable partial prostheses and complete prostheses: case reports. Quintessence Int, 25,239-243.

Casagrande L, Dalpian DM, Ardenghi TM, et al, 2013. Randomized clinical trial of adhesive restorations in primary molars. 18-month results. Am J Dent, 26,351355.

Chadwick BL, Evans DJ, 2007. Restoration of class II cavities in primary molar teeth with conventional and resin modified glass ionomer cements: a systematic review of the literature. Eur Arch Paediatr Dent, 8,1421.

Croll TP, Bar-Zion Y, Segura A, Donly KJ, 2001. Clinical performance of resin-modified glass ionomer cement restorations in primary teeth. A retrospective evaluation. J Am Dent Assoc, 132,1110-1116.
Dhar V, Hsu KL, Coll JA, et al, 2015. Evidencebased Update of Pediatric Dental Restorative Procedures: Dental Materials. J Clin Pediatr Dent, 39,303-310.

Donly KJ, Garcia-Godoy F, 2002. The use of resinbased composite in children. Pediatr Dent, 24,480 488.

Eberhard H, Hirschfelder U, Sindel J, 1997. Compomers--a new bracket bonding generation in orthodontics? J Orofac Orthop, 58,62-69.

Exterkate RA, Damen JJ, Ten Cate JM, 2005. Effect of fluoride-releasing filling materials on underlying dentinal lesions in vitro. Caries Res, 39,509-513.

Figueiredo De Magalhaes M, Neto Ferreira RA, Grossi PA, De Andrade RM, 2008. Measurement of thermophysical properties of human dentin: effect of open porosity. J Dent, 36,588-594.

Fleming GJ, Burke FJ, Watson DJ, Owen FJ, 2001. Materials for restoration of primary teeth: I. Conventional materials and early glass ionomers. Dent Update, 28,486-491.

Food, Drug Administration HHS, 2010. Dental devices: classification of dental amalgam, reclassification of dental mercury, designation of special controls for dental amalgam, mercury, and amalgam alloy; technical amendment. Final rule; technical amendment. Fed Regist, 75,33169-33170.

Forsten L, 1998. Fluoride release and uptake by glass-ionomers and related materials and its clinical effect. Biomaterials, 19,503-508.

Frencken JE, Pilot T, Songpaisan $\mathrm{Y}$, Phantumvanit $P$, 1996. Atraumatic restorative treatment (ART): rationale, technique, and development. J Public Health Dent 56:135-140; discussion 161-133.

Fuks $A B, 2015$. The use of amalgam in pediatric dentistry: new insights and reappraising the tradition. Pediatr Dent, 37,125-132.

Garcia-Godoy F, 2000. Resin-based composites and compomers in primary molars. Dent Clin North Am, 44,541-570.

Gladys S, Van Meerbeek B, Braem M, Lambrechts P, Vanherle G, 1997. Comparative physicomechanical characterization of new hybrid restorative materials with conventional glassionomer and resin composite restorative materials. J Dent Res, 76,883-894.

Gross LC, Griffen AL, Casamassimo PS, 2001. Compomers as Class II restorations in primary molars. Pediatr Dent, 23,24-27. 
Guelmann M, Mjor IA, 2002. Materials and techniques for restoration of primary molars by pediatric dentists in Florida. Pediatr Dent, 24,326-331.

Guggenberger R, May R, Stefan KP, 1998. New trends in glass-ionomer chemistry. Biomaterials, 19,479-483.

Hatrick CD, Eakle WS, 2016. Dental Materials-Clinical applications for dental asistants and dental hygienists. 3rd ed. Elsevier, St. Louis. s: 19-27.

Hesse D, Bonifacio CC, Guglielmi Cde A, et al, 2015. Low-cost glass ionomer cement as ART sealant in permanent molars: a randomized clinical trial. Braz Oral Res, 29.

Hickel R, Kaaden C, Paschos E, et al, 2005. Longevity of occlusally-stressed restorations in posterior primary teeth. Am J Dent, 18,198-211.

Innes NP, Ricketts D, Chong LY, et al, 2015. Preformed crowns for decayed primary molar teeth. Cochrane Database Syst Rev 12:CD005512.

Itota T, Al-Naimi OT, Carrick TE, Yoshiyama $M$, Mccabe JF, 2005. Fluoride release and neutralizing effect by resin-based materials. Oper Dent, 30,522527.

Kan KC, Messer LB, Messer HH, 1997. Variability in cytotoxicity and fluoride release of resin-modified glass-ionomer cements. J Dent Res, 76,1502-1507.

Kopperud SE, Tveit AB, Gaarden T, Sandvik L, Espelid I, 2012. Longevity of posterior dental restorations and reasons for failure. Eur $\mathrm{J}$ Oral Sci, $120,539-548$.

Kotsanos N, Arizos S, 2011. Evaluation of a resin modified glass ionomer serving both as indirect pulp therapy and as restorative material for primary molars. Eur Arch Paediatr Dent, 12,170-175.

Kramer N, Frankenberger R, 2007. Compomers in restorative therapy of children: a literature review. Int $J$ Paediatr Dent, 17,2-9.

Loomans B, Hilton T, 2016. Extended Resin Composite Restorations: Techniques and Procedures. Oper Dent, 41, 58-67.

Luglie PF, Campus G, Chessa G, et al, 2009. Literature Review: Dental Amalgam Fillings and Health Effects, American Dental Association Council on Scientific Affairs, Access: [http://www.ada.org/en/ /media/ADA/

Member\%20Center/Flles/amalgam_literature_review_ 0907].

Mata AF, Bebermeyer RD, 2006. Stainless steel crowns versus amalgams in the primary dentition and decision-making in clinical practice. Gen Dent, 54,347-350; quiz 351, 367-348.
Metz I, Rothmaier K, Pitchika V, et al, 2015. Risk factors for secondary caries in direct composite restorations in primary teeth. Int $\mathrm{J}$ Paediatr Dent, 25,451-461.

Mickenautsch S, Yengopal V, Banerjee A, 2010. Pulp response to resin-modified glass ionomer and calcium hydroxide cements in deep cavities: A quantitative systematic review. Dent Mater, 26,761-770.

Qvist V, Laurberg L, Poulsen A, Teglers PT, 2004. Eight-year study on conventional glass ionomer and amalgam restorations in primary teeth. Acta Odontol Scand, 62,37-45.

Ramires-Romito AC, Wanderley MT, Oliveira MD, Imparato JC, Correa MS, 2000. Biologic restoration of primary anterior teeth. Quintessence Int, 31,405-411.

Roberts HW, Berzins DW, Charlton DG, 2009. Hardness of three resin-modified glass-ionomer restorative materials as a function of depth and time. J Esthet Restor Dent, 21,262-272.

Santos RL, Moura Mde F, Carvalho FG, et al, 2014. Histological analysis of biocompatibility of ionomer cements with an acid-base reaction. Braz Oral Res, 28

Sengul F, Gurbuz T, 2015. Clinical Evaluation of Restorative Materials in Primary Teeth Class II Lesions. J Clin Pediatr Dent, 39,315-321.

Somani R, Jaidka S, Singh DJ, Sibal GK, 2016. Comparative Evaluation of Shear Bond Strength of Various Glass Ionomer Cements to Dentin of Primary Teeth: An in vitro Study. Int J Clin Pediatr Dent, 9,192-196.

Soncini JA, Maserejian NN, Trachtenberg F, Tavares M, Hayes C, 2007. The longevity of amalgam versus compomer/composite restorations in posterior primary and permanent teeth: findings From the New England Children's Amalgam Trial. J Am Dent Assoc, 138,763-772.

Tedesco TK, Bonifacio CC, Calvo AF, et al, 2016. Caries lesion prevention and arrestment in approximal surfaces in contact with glass ionomer cement restorations - A systematic review and meta-analysis. Int J Paediatr Dent, 26,161-172.

Tran LA, Messer LB, 2003. Clinicians' choices of restorative materials for children. Aust Dent $\mathrm{J}$, 48,221-232.

Waggoner WF, 2015. Restoring primary anterior teeth: updated for 2014. Pediatr Dent, 37,163-170. 
White JM, Goodis HE, Marshall SJ, Marshall GW, 1994. Sterilization of teeth by gamma radiation. J Dent Res, 73,1560-1567.

Yadav G, Rehani U, Rana V, 2012. A Comparative Evaluation of Marginal Leakage of Different Restorative Materials in Deciduous Molars: An in vitro Study. Int $J$ Clin Pediatr Dent, 5,101-107.

Yang ZP, Chang CS, 1990. A 3-year follow-up of a homotransplanted tooth from a tooth bank. J Endod, 16,34-37.

Yeolekar TS, Chowdhary NR, Mukunda KS, Kiran NK, 2015. Evaluation of Microleakage and Marginal Ridge Fracture Resistance of Primary Molars Restored with Three Restorative Materials: A Comparative in vitro Study. Int J Clin Pediatr Dent, 8,108-113.

Yildiz E, Simsek M, Pamir Z, 2015. Fracture strength of restorations in proximal cavities of primary molars. Scanning.

\section{Yazışma Adresi:}

Merve Safa MUTLUAY

Kırıkkale Üniversitesi

Diş Hekimliği Fakültesi Pedodonti AD

Kırıkkale, Türkiye

Tel : + 903182244927

Faks : + 903182250685

E-mail: mervkrts@hotmail.com 